(8R) Nepal Journal of Obstetrics and Gynecology 2

NJOG

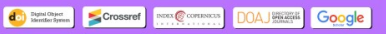
CASPA JaL Nop [t: An Oficicial Scientific Publication

\section{CORRESPONDENCE}

Dr. Alka Shrestha

Department of Obstetrics and Gynecology,

Poropakar Maternity and Women's Hospital, Thapathali, Kathmandu, Nepal

Email:

shresthaalka@gmail.com Phone: 9841789820

Received: June 7, 2021

Accepted: June 15, 2021

\section{Citation:}

Shrestha A, Dangal G, Tiwari K Bladder injury: a complication of Transobturator Tape surgery. Nep J Obstet Gynecol. 2021;16 (32):139-140. DOI: https:// doi.org/10.3126/ njog.v16i1.37920

\title{
Bladder Injury: A complication of Transobturator Tape Surgery
}

\author{
Alka Shrestha ${ }^{1}$, Ganesh Dangal ${ }^{2}$, Kenusha Devi Tiwari ${ }^{2}$ \\ ${ }^{1}$ Department of Obstetrics and Gynecology, Poropakar Maternity and \\ Women Hospital, Nepal \\ ${ }^{2}$ Department of Obstetrics and Gynecology, Kathmandu Model Hospital, \\ Nepal
}

\section{ABSTRACT}

Minimally invasive vaginal surgeries are often a preferred mode of surgical treatment of stress urinary incontinence. It is associated with fewer complications. However, complications including hemorrhage, voiding dysfunction, infection, pain, skin infection and erosion, and bladder injuries are observed. We encountered intraoperative bladder injury in a 40-year-old female patient with stress urinary incontinence who underwent transobturator tape (TOT) surgery. Cystoscopy demonstrated a small defect post procedure. She was managed conservatively with foley catheterization for 2 weeks following TOT procedure. She was dry and continent upon follow up.

Keywords: bladder injury, transobturator tape, cystoscopy

\section{INTRODUCTION}

Stress urinary incontinence (SUI) is an involuntary loss of urine especially seen in middle age parous women which develops as a result of activities like coughing, laughing, heavy weight lifting walking and running. ${ }^{1}$ An estimated prevalence for urinary incontinence is nearly $30 \%$ in women aged 30-60 years, with approximately half of the cases attributed to $\mathrm{SUI}^{2}$

The initial treatment for SUI include lifestyle interventions, pelvic floor muscle training, and bladder training followed by surgery, which is an option for women whose quality of life is still impaired after a diagnosis of genuine stress incontinence has been confirmed. ${ }^{2}$ Vaginal sling procedure like Transobturator Tape (TOT) method introduced by Delorme in 2001 is one of the common surgical modality being used in our country. ${ }^{2}$ Common complication encountered are hemorrhage, bladder injury, bowel injury, urethral injury, vaginal laceration, tape erosion and infection. ${ }^{3}$ Bladder injuries is one of the rarely reported challenging complications that might occur after TOT. ${ }^{1}$

\section{CASE}

A 40 years female para 2 living 2, nondiabetic, non-hypertensive, came to outpatient department with complaint of involuntary leakage of urine for 10-12 years aggravated since past 3 years upon running and brisk walking affecting her quality of living. On examination stress test was positive and no associated abdominal mass and pelvic organ prolapse noted. She was diagnosed a case of genuine stress urinary incontinence and planned for transobturator tape placement.

We performed outside-in technique (Figure 1) and there was a bladder injury confirmed later by cystoscopy.

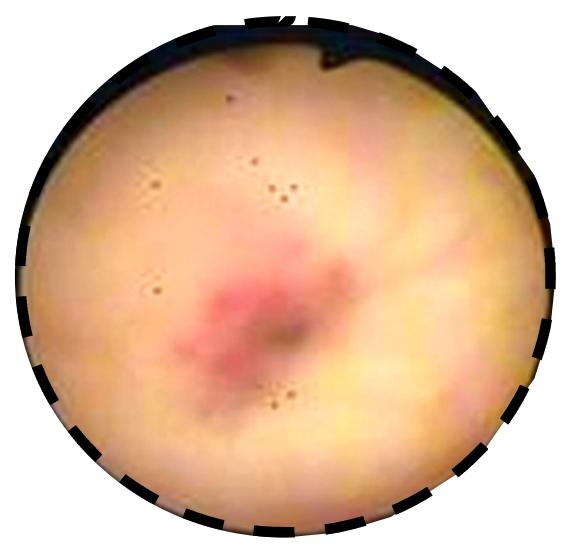

Figure-1: Cystoscopy view of bladder puncture 
TOT was applied in outside in technique with accidental bladder injury was noted with sudden gush of fluid coming out. Diagnostic cystoscopy was done intraoperaively. It showed a $0.5 \mathrm{~cm}$ small defect over posterior dome of the bladder. TOT tape was reapplied and secured at midurethral region. Patient was planned for conservative management with continuous drainage of urinary bladder using foley catheter. Foley catheter was continued for 10 days. Patient was dry at 6 months follow up. She is dry and continent now.

\section{DISCUSSION}

In the current scenario, sling surgery is the treatment of choice for stress urinary incontinence. It has gain popularity over colposuspension as it is less invasive and can be done under regional or local anesthesia. The aim of TOT technique as compared to other sling method was to decrease the risk associated with the passage of trocars in the retropubic space, especially the risk of bladder or bowel injury and to restoration of hammock-like support. ${ }^{3,4}$

A small skin incision is made on either side $1.5 \mathrm{~cm}$ lateral to the ischiopubic ramus. Using specially designed needles the obturator membrane is perforated and then the needle is turned medially. It is then guided with a finger in the vaginal incision to exit in the vagina. The tape is then loaded on to the needle and pulled through the skin incision. Tension is adjusted so that a dissecting scissors can lie flat easily between the tape and urethra. The incisions are closed with absorbable sutures. ${ }^{4}$

The tubing attached to the helical passer is placed within the introducer (wing guide) and rotated to exit through the groin incisions. The tubing is then pulled from the passer as the passer is brought back out through the vaginal incision and the tape is pulled through. ${ }^{4}$

The rate of postoperative voiding problems with transobturator tapes appears to be similar to that with retropubic slings. ${ }^{5}$ The most common intraoperative problem encountered is hemorrhage. ${ }^{5}$ During the TOT procedure bladder perforation is generally less common because retro-peritoneal route is avoided.

In a study by Magon et $\mathrm{al}^{2}$, they reported one case of bladder injury in his study. Minaglia et $\mathrm{al}^{5}$, has reported three cases of bladder injury among 61 TOTs applied. Bladder injury was confirmed by cystoscopy and continues drainage of bladder was drain via foley catheter was done for 1 week. All three cases were dry and continent. ${ }^{5}$ In a study by Tamussino et $\mathrm{al}^{3}, 0.4 \%$ of bladder perforation was noted among 2543 cases. They reported the incidence of bladder injury comparatively high during outside in technique than inside out technique. Complication of mesh eroding the bladder has also been reported in studies by Bayrak et al. ${ }^{1}$

\section{CONCLUSIONS}

Transobturator tape is a simple and effective procedure for treatment of stress urinary incontinence. The associated complications are very few and routine cystoscopy is not indicated. However, surgeon must be very vigilant about the risk of bladder injury and well trained to perform cystoscopy if needed. Small injuries can be managed conservatively with continuous bladder drainage.

\section{REFERENCES}

1. Bayrak Ö, Erbağcı A, Şen H, Erturhan S, Yağcı F, Seçkiner İ. Transvaginal repair of unrecognized bladder injury after transobturator tape surgery. Turkish J Urol. 2013;39(4):277.

2. Magon N, Chopra SV. Transobturator tape in treatment of stress urinary incontinence: it is time for a new gold standard. North Am J Med Sci. 2012;4(5):226.

3. Tamussino K, Hanzal E, Kölle D, Tammaa A, Preyer O, Umek W, et al. Transobturator tapes for stress urinary incontinence: results of the Austrian registry. Am J Obstet Gynecol. 2007;197(6):634-e1.

4. Imran R, Kearney R. Surgical management of stress urinary incontinence. Obstet Gynaecol Reprod Med. 2016;26(1):20-5.

5. Minaglia S, Özel B, Klutke C, Ballard C, Klutke J. Bladder injury during transobturator sling. Urol. 2004;64(2):376-7.

6. Schanz JP, Arriola PR, Fernández XT, Ortiz EB. Trans obturator tape (TOT) for female stress incontinence. Experience with three years follow-up in 200 patients. Actas Urologicas Espanolas. 2007;31(10):1141-7. 